\title{
Working toward a socially just curriculum in South Africa: A collaborative autobiographical narrative inquiry
}

\section{Marguerite Müller}

School of Education Studies, Faculty of Education, University of the Free State, Bloemfontein, South Africa mullerm@ufs.ac.za

\section{Collins Motai}

Lecturer, National Certificate Vocational (NCV) programme, Higher Education \& Training, Motheo TVET College, Bloemfontein, South Africa motaid@motheotvet.co.za

\section{Matshepo Nkopane}

Lecturer, National Certificate Vocational (NCV) programme, Higher Education \& Training, Motheo TVET College, Bloemfontein, South Africa nkopanee@motheotvet.co.za

\section{Tiisetso Mofokeng}

English and Sesotho teacher, Jimmie Roos School, Dewetsdorp, South Africa tiisetsomofokeng32@gmail.com

\section{Nthatuoa Lephatsoe}

English language and literature teacher, St. Stephens High School, Mohale's Hoek, Lesotho nthalephatsoe@gmail.com

\section{Ryno Mouton}

Deputy Principal, North Primary School, Sasolburg, South Africa rynom@ymail.com

(Received: 14 May 2018; accepted: 25 October 2018)

\section{Abstract}

In this article, we foreground the lived experiences of a group of post-graduate education students at the University of the Free State who explored issues of social justice in the curriculum. Our contextual and local experiences are situated as part of a call for the decolonisation of the curriculum. In this context, we view 
curriculum as an autobiographical, lived, and storied practice (Pinar, 2012). Through our creative collaborative narrative, we focus on teacher identity and experience since this has been shown to have a major impact on the curriculum (Clandinin \& Connelly, 2000). Furthermore, we use Kumashiro's (2002) conceptualisation of antioppressive education to highlight the messiness and discomfort of our experiences as we relearn, unlearn, and trouble oppressive knowledge in order to imagine alternatives. We posit anti-oppressive education as part of the social justice project as a useful theoretical stance in thinking around the decolonisation of the curriculum. In this article, we use a critical qualitative inquiry (Denzin, 2017) to explore what a process of decolonisation might look like; we offer an entangled view of how a collaborative narrative research methodology, identity, experience, and theory form part of the process of working towards a socially just and decolonised curriculum. Our article contributes to an existing body of work that uses collaborative and narrative methods to research issues of social justice. However, since much of the international literature on social justice education and curriculum is written in contexts far removed from our everyday experiences, we wish to make a unique contribution that is rooted in our local context and that highlights the unique experiences of South African teachers in relation to issues of social justice and the decolonisation of the curriculum.

Keywords: collaborative research; autobiographical narrative; decolonisation; social-justice; anti-oppressive education.

\section{A call for change}

The call for decolonised higher education has intensified in recent years. This is evident from the student protest movements that, as Jansen (2017) noted, placed great emphasis on a decolonised university curriculum. As South African educators, we need to think about how we can respond to the call for a decolonised curriculum. Furthermore, we need to think about how our research practices can inform and be informed by this response so our thinking, about curriculum change, transformation, and decolonisation should be informed by research practices that make such change possible. Our engagement with decolonisation must thus be twofold-first, in our experimentation with a different way of doing research, and second, in the theoretical sphere of anti-oppressive education where we locate our experiences of change and social justice.

In this article, we use a critical qualitative inquiry (Denzin, 2017) to explore what a process of decolonisation might look like. We are interested in how our identity and experiences can guide our understanding of curriculum as entangled with transformation, decolonisation, and social justice. In this exploration we use anti-oppressive education as a theoretical stance to help us think through issues of social justice, decolonisation and curriculum. Furthermore, our critical inquiry is located in a collaborative, autobiographical, and narrative methodology that enables us to address issues of power relationships with research contexts as well as foreground the contextual and local experiences of South African educators. We offer an entangled view of how a collaborative narrative research methodology, experience, and literature all form part of the process of working towards a socially just and decolonised curriculum. In the next section, we discuss some of the literature and theories on decolonisation and social justice. We highlight specifically the theory of anti-oppressive education to explore the ways in which it might help us move towards a decolonised curriculum. Following that, we discuss our method of collaborative narrative research as it becomes entangled with our theoretical understanding of decolonisation and social justice. 


\section{A discussion of some literature and theories on decolonisation and social justice}

Here we unpack some of the literature and theories on decolonisation and social justice as it relates to our understanding and context. Mackinlay and Barney (2014) have pointed out that "[d]ecolonisation is a concept that takes on different meanings across different contexts" (p. 55. Nonetheless, it can be understood roughly to encompass a project that resists Eurocentrism, works to address the harm caused by colonial domination, and moves towards more socially just practices in the field of education. It should be noted, however, that there are many contradictions and controversies surrounding the issue of decolonisation in education. Scholars like Jansen (2017) and Keet, Sattarzadeh, and Munene (2017) have warned that it might be part of a new academic fad that might just disappear with time as it goes out of fashion, without having had any real or transformative impact on our curriculum or practices. They argue that educators should not simply get caught up in this latest buzz word but should, rather, work with students to "contribute to the self-clarification of the struggles within our universities" (p. 5). In this article, we hope to contribute to this selfclarification by using collaborative, autobiographical narratives to create a reflexive and honest engagement with ourselves and our experiences as we move towards a socially just, decolonised, and transformed curriculum.

Jansen (2017) has stated that "[t]eachers interpret the curriculum to students on the basis of their own experiences, backgrounds, politics, and preferences" (p. 169). From this, we understand that the experiences of educators - our own experiences—should play a pivotal role in working towards a decolonised curriculum. The manner in which we engage with these experiences is also significant in the context of decolonisation. Mbembe (2016) has reminded us that

Western epistemic traditions are traditions that claim detachment of the known from the knower. They rest on a division between mind and world, or between reason and nature as an ontological a priori. They are traditions in which the knowing subject is enclosed in itself and peeks out at a world of objects and produces supposedly objective knowledge of those objects. The knowing subject is thus able to know the world without being part of that world and he or she is by all accounts able to produce knowledge that is supposed to be universal and independent of context. (pp. 32-33).

By calling attention to the problematics of Western traditions of knowledge as something that resides outside of the subject, and as something that can be objectively investigated and found, Mbembe (2016) has helped us to trouble existing and prevailing research traditions in which researchers are often positioned as knowers who make knowledge claims about the known. He went on to say that "there is a consensus that our institutions must undergo a process of decolonization both of knowledge and of the university as an institution" (p. 33). In this article, we look specifically at how we can create an alternative approach to what counts as knowledge in terms of social justice and decolonisation of the curriculum. We do this by foregrounding the voice, identity, and knowledge of educators who engage with 
curricula in terms of what Aoki $(1993,2005)$ described as a lived experience and what le Grange has thought of as an autobiographical one in their everyday world.

In moving towards a decolonised approach to research practice and methodology, we need, therefore, to come to a new understanding of subjectivity, one in which the knower and the known become conflated. In moving towards this new understanding, we need to think of new ways of knowing because, as Mbembe (2016) has pointed out, "[W]e might be fighting battles of the present and the future with outdated tools [and] [w] need more profound understanding of the situation we find ourselves in today if we are to better rethink the university of tomorrow" (p. 37). We try to come to a more profound understanding of the situation in which we find ourselves today by looking at the shared experiences that brought us to this point of collaboration. We, as the educators who participated in this study, form an assemblage of histories and experiences in coming from different places but ones that move us in the same direction towards what Zembylas (2017) referred to as a shared responsibility. The way we understand and use decolonisation in our work is as a compelling and productive force that necessitates our working towards new ways of being, researching, and teaching in the Southern African context.

\section{Linking decolonisation to social justice}

In this section, we extend the discussion of how our work relates to decolonisation to issues of social justice and we zoom in specifically on the theory of anti-oppressive education. The critical theorist Paulo Freire (1985) stressed the importance of recognising the educator and the student as historical beings. As South African educators, we do not come into the classroom with clean slates. In fact, most of us come from a divided and unequal society in which we function inside oppressive structures and systems. Yet, we have an official commitment to a socially just curriculum as is enshrined in almost all the Curriculum Assessment Policy Statements (CAPS) (2012), documents that currently serve as curriculum and policy guidelines for South African educators. With this in mind, we set out to understand how our identities and experiences can influence curriculum transformation for a more socially just and decolonised educational system. In our research, our teacher identities and experiences are foregrounded in line with our view of curriculum as an autobiographical, lived, and storied practice (Pinar, 2012). In this project, we approach social justice as more than just a theoretical concept that we need to embrace in our teaching. Rather, it is an active process in which our identities and experiences shape and influence what we teach and how we teach it.

Bell (2007) described social justice as both a process and a goal.

The process for attaining the goal of social justice, we believe, should be democratic and participatory, inclusive and affirming of human agency and human capacities for working collaboratively to create change ... The goal for social justice education is to enable people to develop the critical analytical tools necessary to understand oppression and their own socialization within oppressive systems, and to develop a 
sense of agency and capacity to interrupt and change oppressive patterns and behaviours in themselves and in the institutions and communities of which they are part. (p. 2)

Our research project embraces both the process and the goal of social justice. Our process is highlighted through our methodological approach, which, because it is participatory, inclusive, and affirming of human agency, makes it possible for us to work collaboratively to create change. Furthermore, our project has the goal of helping us locate and recognise our experiences with oppression and oppressive systems through an engagement with our autobiographical narratives. This is in line with Bell and Desai's (2011) view that "[s]ocial justice practices at their best should also awaken our senses and the ability to imagine alternatives that can sustain the collective work necessary to challenge entrenched patterns and institutions and build a different world" (p. 287). We approach this imagining of alternatives collaboratively as we explore how to interrupt and change our own behaviour and, by extension, the educational institutions and communities of which we are part.

Teaching for social justice is a pedagogical method that enables teachers to implement and deliver a curriculum that is fair and equal and does not discriminate against learners because of their differences. Our study maintains that for social justice to be possible, teachers need to collaborate with other teachers to become activists of social transformation. However, this might be easier said than done. Francis and Hemson (2007) explored the actions of M.Ed. students in a course on pedagogy in social justice education and how these clashed with an anti-oppressive approach. They show how problematic it is to think that educators can simply change from practising oppression to offering liberation, since, in reality, the move towards social justice in education is difficult, imperfect, and challenging. Keeping this in mind, our study highlights the need to engage collaboratively with our experiences as we critically reflect and seek new knowledge for building relations and developing a culture of integrity, respect, and care for others. The collaborative aspect of our study is thus an important expression of our understanding of social justice. It links to our view of decolonisation as necessitating a new way of doing research in order to foreground the local realities and experiences of educators. These experiences are framed within a larger project of social justice and transformation.

\section{A theory of anti-oppressive education}

Here we discuss the theory of anti-oppressive education and how we used it to make sense of our past and present experiences in South African education. We locate our study in the antioppressive theory of Kevin Kumashiro (2002), who emphasized the importance of troubling our existing knowledge in a process of unlearning, relearning, and looking beyond what we know. He described four ways to conceptualise anti-oppressive education. The first way is "education for the other" (p. 28), in which the educators strive to improve the experience of students who are othered. This approach views the school essentially as a harmful space in which othered students are treated in harmful ways. The goal for educators working towards anti-oppressive practice should then be to teach to all and embrace the diversity of students as 
raced, gendered, sexually diverse, and classed individuals. The second approach is "education about the other" (p. 33). The aim here is to create awareness and knowledge about the other. Such knowledge often relies on normative values - the so-called right and authentic truthbut this can be misleading and distorted, and based on stereotypes, and is therefore partial and biased knowledge. Kumashiro's third approach to conceptualising anti-oppressive education is "education that is critical of privileging and othering" (p. 37). Here, the focus is shifted from otherness and emphasises how some groups are favoured, normalised, and privileged. Schools are seen to be spaces that transmit ruling ideologies and reproduce existing social orders; we have to recognise, critique, and understand such social inequality. This involves unlearning what was previously learned as normal and normative as Kumashiro has made clear. The fourth and final approach is "education that changes the self and society" (p. 39). This implies that we must constantly look beyond what is being said for the silences and contradictions in our knowledge. Following this framework means that we have to revisit our desire to ignore certain things in our narratives.

Kumashiro (2002) argued that anti-oppressive theory is influenced by poststructuralism and therefore allows us to deconstruct the self/other binary that can be viewed as rooted in colonial discourse, so a move towards decolonisation must also be a move beyond the self/other distinction. Anti-oppressive theory helps us to trouble the self/other binary through our theoretical understanding and to extend it to our methodological approach as we try to move beyond binaries like knower/known, researcher/participant, subject/object, and so on.

Furthermore, anti-oppressive theory is rooted in critical theory, which helps us examine the connection between social identity, unequal power relationships, and oppression. Critical theory has been influential in helping education researchers develop a reflexive stance towards their teaching. In exposing the limitations of critical theory in a post-conflict society, Jansen (2009) has called for a post-conflict pedagogy. He has argued that although critical theory shows us the systematic and institutionalised character of oppression, it is limited in "making sense of troubled knowledge and for transforming those who carry the burden of such knowledge . . . Critical theory receives and constructs the world as divided between black and white, working and privileged classes, citizens and illegal immigrants, men and women, straight and queer, oppressors and oppressed; its dialogical pretences notwithstanding, the world is torn among rival groups" (p. 256). We find the anti-oppressive theory of Kumashiro (2002) useful because it enables us to acknowledge the limits of what we know and encourages us to move beyond our current knowledge.

Given this understanding of anti-oppressive education, we are able to peruse a plurality of knowledge rooted in local and small micro-narratives that honour the past and present experiences of South African teachers. The multiplicity of understanding that comes from collaborative work of this nature serves to trouble the colonial ideals of universal knowledge and grand overarching narratives. We hope that our study can contribute to the plurality of knowledge through contextual and local responses as we work towards an understanding of a decolonised curriculum. 


\section{A research methodology that responds to the call for change}

In this section, we discuss our methodological approach and link it to our theoretical understanding of decolonisation, social justice, and anti-oppressive education. In line with our view of knowledge as a plurality, we used a collaborative narrative method to engage critically with our experiential knowledge of social justice in the curriculum. We chose a narrative method for our project because "narrative researchers continue to be compelled by the relationship between their work and possibilities for change and social justice" (Chase, 2011, p. 427). A narrative approach is well suited to address issues of complexity and cultural and human centeredness because of its capacity to record and retell events that have had the most influence on us. We locate narrative in the broader area of critical qualitative methodologies that are well suited to research using critical perspectives and theories. Ulmer (2017) stated that critical qualitative methodology has

transformative aims by attending to race, ethnicity, gender, sexuality, class, culture, spirituality, ability, language, and other aspects of identity. Critical methodologies welcome all of humanity to contribute knowledge. Because critical inquiry strives to be inclusive, anyone can offer insights based on their own socio-cultural experiences. As a result, robust bodies of literature have developed around Critical Race Theory, as well as feminist, LGBTQ, Indigenous, and dis/ability studies. These methodologies have been applied most often within interpretivist frames that underscore the importance of honouring marginalized people's experiences, perspectives, voices, and participation in research. (p. 834)

The autobiographical aspect of the research is thus necessary since it offers all participants the chance to contribute insights into their own socio-cultural experiences in relation to education and social justice.

Denzin (2017) emphasised the role of the researcher in an historical present where the need for social justice is becoming more and more evident. He stated that " $t]$ he pursuit of social justice within a transformative paradigm challenges prevailing forms of inequality, poverty, human oppression, and injustice. This paradigm is firmly rooted in a human rights agenda" (p. 8). The local lives of the researcher and participant are thus important since " $[t]$ he focus will be on human beings as universal singulars, individuals, and groups universalizing in their singularity the transformative life experiences of their historical moment" (p. 9). Denzin (2008) described interpretative biography or autoethnography as a method of inquiry in which we re-tell or re-perform our lived experiences. This method does not necessarily concern itself with giving what might be called a true or accurate representation of what was or is, but, rather, with the possibilities of knowing what our biographies make possible. As Leavy (2009) pointed out, "[A]utobiographic work is suited to identity research that seeks to confront stereotypes that keep some groups disenfranchised while other groups are limited by their own biased 'common-sense' ideas" (p. 24). In seeking for a local and contextual understanding of how educator identity responds to and shapes ideas of social justice and 
decolonisation, we embarked on a form of collaborative narrative inquiry that is autobiographical in nature.

Furthermore, the collective biographical (see Davies \& Gannon, 2012) aspect of our project is important because of its "potentially radical, political, disruptive, and creative approach to inquiry, one that offers multiple possibilities and openings for researchers" (Wyatt, Gale, Gannon, \& Davies, 2018, p. 738). By abandoning the idea of an individualised author, we seek to open up the multiplicity of the assembled subjectivities that stand in contrast to the colonial desire of categorisation and order and the subsequent neoliberal demand for competitive individualism (see Wyatt et al., 2018). As critical qualitative researchers, we used a collaborative autobiographical narrative methodology to explore the entanglement of our day-to-day experiences and our identities in relation to issues of social justice in the curriculum. Collaborative writing responds to the aims of an inquiry that seeks to explore the not yet known, or the space beyond what we know. By doing this, we hope to respond to the call for change in our context by disrupting overarching and dominant understandings of social justice in the curriculum and by highlighting the nuances of our local and contextual experiences.

\section{Our collaborative autobiographical narrative}

To sum up briefly, in the previous two sections we explained how our theoretical understandings and methodological approach underscore a research project in which we explore issues of educator identity, social justice and decolonisation through a collaborative autobiographical method. In this section, we explain the project in more detail and present the combined narrative in which we explore some of our diverse experiences in pre- and postapartheid South Africa. Through this, we hope to explore our understanding of bias, equity, diversity, access, and power in the curriculum.

\section{Generating the narratives}

This article is the culmination of a collaborative study on social justice in the curriculum that we conducted as a group during a PGDip (Postgraduate Diploma) module at the University of the Free State in 2017. As part of the PGDip course students are required to submit a research project (capstone project) in which they complete a mini dissertation based on a theme that relates to the coursework they have done. Students typically work on similar themes in groups of five to eight under the supervision of a lecturer who leads the project. Our group consisted of five students doing their capstone research project and one principal investigator. The students on the project worked in diverse educational settings, ranging from primary school and high school to Technical and Vocational Education and Training (TVET) colleges. Our group consisted of people who identify with different and diverse categories of gender, race, sexuality, language, class, ability, and other social categories. Coming from diverse educational and social backgrounds and working for various educational institutions, we were in the privileged position of being able to take a broad view of our experiences with social justice in a variety of educational settings. 
In this project, we used our own autobiographical narratives of experience and memory of social justice in relation to the curriculum to generate data. We created a written data set by writing our autobiographical narratives in response to a set of question prompts adapted from Cochran-Smith et al. (1999) that served to shape our research protocol. The following questions were used by all of us to write our initial autobiographical narrative.

- What does social justice mean to you?

- Narrate your life-story (brief but focus on key areas of growth/change/awareness you have undergone in terms of social justice).

- What are your experiences as educators in relation to the cycles of oppression (race, gender, culture, language, ability, sexuality, etc.) that operate in our society and schooling institutions?

- Describe a critical event in your own schooling during which you perceived an absence of social justice.

- Describe a critical event in your teaching experience during which you perceived an absence of social justice.

- If our classrooms were socially just, what would they look like?

- What are the implications of social-justice issues in our curriculum?

- How do our own experiences and identities influence the experiences and identities of our students?

- How do our own experiences and identities help/hinder us in working towards social justice?

After we generated the individual written narratives, we shared them with each other and then got together as a group to discuss our narrative responses and collaboratively interpret our various stories. The combined collaborative narrative was created from five individual narratives. Each participant chose a pseudonym for her or his individual character. The different narratives are brought together in a conversation about past and present experiences with oppression and social justice in educational contexts. The language used in the narrative is purposefully presented in informal conversational South African English, with no language editing having been done so as to honour the authentic contributions of the authors (all of whom use English as their second or third language). In the next section we will offer a brief explanation of how the narratives were interpreted and, thereafter, an exploration of the narratives.

\section{Interpreting the narratives}

Our aim in this research project was to shape a collaborative autobiographical narrative about issues of social justice in education. Chase (2011) stated that narrative researchers "turn the analytic lens fully and specifically on themselves as they write, interpret, or perform narratives about their own culturally significant experiences" (pp. 422-423). Our interpretation or analysis of our narrative responses is thus informed by a narrative tradition in which interpretation happens throughout the research process, and in which the researcher uses "themes either within or across an individual's experience and in the social setting" 
(Clandinin \& Connelly, 2000, p. 123) in order to create stories in a process of "storying and restorying" (Polkinghorne, 1995, p.11). Furthermore, our interpretation is guided by a collaborative approach to analysis. Collaborative analysis becomes useful when the interest of a research project seems not to be served by a single perspective but requires the engagement of multiple perspectives (Cornish, Gillespie, \& Zittoun, 2013).

In our interpretation, we thus collaboratively re-storied our individual autobiographical narratives in order to formulate a combined narrative that responds to the theory of antioppressive education (Kumashiro, 2000) as outlined above. From this theory, we were able to identify certain themes that helped us engage with our narrative experiences in order to foreground issues of social justice. Some of the themes that we identified were messiness, discomfort, harmful spaces, othering and being othered, relearning and unlearning, and change of the self and society. In the following section, we show how our collaborative narratives helped us locate some of the themes of social justice and anti-oppressive education as identified in our experiences. We acknowledge that our narrative is partial and incomplete. It is not meant to be a comprehensive or generalisable narrative of experiences of social justice in education; it is meant to be an intimate engagement with some of the issues that arose from our micro-social milieus in order to make connections to other educators who work in similar contexts. We aimed to highlight the connections, similarities, and differences in our experiences as we collectively aim to understand the significance of our current moment and envision a way forward in which we do not replicate and repeat the oppression or injustices of the past.

\section{Drawing understanding from each other's narratives}

After we had each written our own individual narrative, ${ }^{1}$ we shared these with each other to see how we could collaboratively identify themes of social justice and anti-oppressive education. Using our written narrative responses to the questions mentioned earlier we traced how our memories and histories from early childhood and our socialisation might have influenced our current understandings. We found that many of the narratives we shared keep the us/them understanding intact. In Camilla's narrative, she locates her early understanding of the binaries of gender, race, and class:

My dad was a police man and my mom worked as a potter in the local hospital. They went on a strike, stayed in jail for a night and they lost their jobs. Mom became a domestic worker; come Christmas I would always get a present from the white lady my mom worked for - an envelope with cash in it. Later, as a learner in an Afrikaans/English school, there was a lot of race division as I still see today. We had these boys in our school that would not sing the national anthem in the parts that was not in their language, but when getting to their language they would sing it out very loudly. 
Craven also speaks of his experience with racial binaries and racial geographies when he started teaching as a white teacher in a school where the majority of the learners were black.

I started my education career in a (ex) Model C school where $90 \%$ of our children came out of the townships ${ }^{2}$ of the town. The children came with taxis to school and we had little to no parent involvement. I was like a father to a lot of the children, especially next to the sports field - parents seldom to never come to support their children. I really saw a different picture about life in my five years teaching at this school and also saw how independent Grade 1 children could be, as I did not experience it like that growing up.

Mary also highlights her experiences with racial binaries at her institution.

In the staffroom there were two big tables with chairs. As you enter the staffroom, the first table you will find only white people - members of the staff seated there and then on the second table only black people - members of the staff. On my first day, I arrived early and sat on nearest seat available to avoid unnecessary interruptions or to show some good manners. There was a white educator who was seated on the very same table and he kept on giving a strange look. It was only later when all members arrived I realized that I am seated on the wrong table. Even today, if you visit our staffrooms in the morning meeting you find the similar set up; it is like there is silent agreement between the both racial groups (black and white educators) not to cross over the other race's territory.

Paterson focused on his experiences with binaries of gender.

When I was in primary, I was not comfortable with the agricultural session where we had to go to the garden. Girls will just put in seed in a hole and the boys had to dig the holes. I always felt isolated because all the other learners, mostly boys, will mock me for being a 'sissy'. The teacher also labelled me as 'a special child who does not want to do anything.'

From the narratives we shared, it became evident that we have all experienced racial, gender, cultural, language, and sexual inequality in educational spaces in some form or another and to some extent. Not surprisingly, there is a particular focus on racial binaries, racial geographies, and racial territorialisation in educational spaces.

Kumashiro (2000) stated that the school can be a harmful place where learners are othered based on their sexuality, gender, race, language, socio-economic background, abilities and/or disabilities. Educators also function in these harmful spaces and are not immune to the kinds

Under Apartheid legislation all South Africans were classified in racial categories as White, Black, Coloured or Indian. Different racial groups were designated to occupy different living spaces by law. Townships or locations were the spaces designated as being for 'Black, Coloured or Indian' South Africans. Townships or locations were commonly found on the outskirts of towns or cities. Suburban spaces that were closer to the city center were designated as 'White' spaces. After the fall of apartheid these segregated living arrangements, although no longer legally enforced, continue to categorize the South African landscape and many South Africans still use the terms township and location. 
of inequalities they produce. From the narratives we shared, it became clear that many of us focused on negative experiences and memories of being othered in educational contexts. Camilla speaks of her experience of feeling othered.

In Grade 6, I was taken to a multiracial school. Here I am, a girl from $\mathrm{kasi}^{3}$, in a school where it was white dominated. Adapting was a bit difficult. I went from being an A student to an underachiever. When I was in primary, where a white teacher ... called all the black learners stupid because we couldn't swim and we would make our parents write us letters that we won't swim. But the most racism or discrimination I got was from my own kind. In most instances, I was told I think I'm better because I can speak Afrikaans - and that actually made me hate speaking it.

In Camilla's narrative, we see the intersections of race, class, culture, and language in educational contexts. Mary also speaks of how other learners at school called her names because of her socio-economic background.

Most of us resided in mud houses, did not have any running water or electricity. I was at the age of six years when I went to school, where I realised that there was something wrong with my family. I saw my family through the eyes of my classmates, who will regularly scold me about my dysfunctional family. Those who lived in brick houses with electricity and a telephone line called the likes of me by names.

Paterson speaks of how teachers made him feel othered based on his stutter and sexual orientation.

When I was in primary, I used to prefer wearing the grey school short pants, unlike the long pants that all boys used to wear. One of my primary school teachers made a remark about how I wear trousers like girls and I am always around girls as if I want to be a girl: 'Ke hore ke qala ho bona moshemane a aparang borikgwe bo motisang chena, ebile a dula a le ka hara banana, kapa ke tharasi' (I have never seen a boy who wears tied pants like this and he is always around girls. Is he gay?). She used the words 'Is he gay?' as a rhetorical question. I felt unsafe and shameful by what she said, especially when all the other learners started laughing and labelling me as gay. In high school, most of my teachers would not allow me to express myself because I was a stutterer. This was a barrier for me as a learner, especially when I had to do an oral presentation using a language that is not my mother tongue because I would become nervous yet trying to avoid any English errors.

Agnes points further to the gender and sexual roles to which learners are expected to subscribe by pointing to her current experience as a teacher.

My school offers subjects like fashion and textiles and woodwork, but learners seem to believe that certain subjects like woodwork should only be taken by boys, and 
fashion and textiles be taken by girls. This has led to some learners discriminating and harassing others for the choice of subjects. Boys would be referred to as ladies for they study subjects 'supposedly meant' for girls, and vice versa. They would also be pushed out of the toilets to be told to join 'other girls.'

The negative experiences we share are from our memories of schooling as well as from our current experiences as educators. Some of us went on to extend our negative experiences into our current understanding to show how reflection on this connection helped us undergo a process of unlearning and relearning. For example, Agnes describes her experiences of discrimination by Indian classmates when she was in school and how she developed hatred towards them.

The school I went to was a private school with more Indian learners than Basotho. The problem there was when our fellow Indian students spoke a harassing and hurtful language which we Basotho could not understand. I say 'hurtful' because we later learned what those words they would say meant. What was most hurtful was that we did not receive any help from the principal because the matter would disappear just like that. We then decided to retaliate by using our own language against our harassers, but to our surprise, we would be punished and promised suspension. 'Who is better than whom in this school?' we always wondered.

However, she goes on to describe how her growing understanding of social justice has helped her to appreciate her current Indian learners and to love them as their teacher.

I must say, all these scarred me for a very long time. Since then, I lost trust in myself. I never thought I could excel in anything. I could not voice my opinion for fear of how people would receive it. I developed hatred for Indians: strong hatred that led me into taking it out on my Indian students at my current school. This had always been my plan of avenging for my past experiences with Indians as a scholar back then. I had now found what I had long awaited. But through my current studying, I have learned about social justice and have realised it is really wrong of me to inflict injustice to anybody. I should be an example.

Furthermore, Craven says that his experiences in an under-resourced school helped him to see how students from poor backgrounds could think critically and solve problems without having all the facilities he had growing up. He realised that learners with far fewer resources could achieve good results if they had support.

The children had lots of potential and were very clever, but going home they did not get support on homework or assignments to be done, so it was only the learners with a lot of self-discipline that achieved good marks. I picked up here while teaching technology that the children are very good problem solvers and can make, literally make something out of nothing; these learners could think for themselves as there was no one to go home to and help them. 
Paterson was also able to see how his negative experiences in education help him in his teaching now.

I believe that as teachers sharing our life experiences will empower our students to pursue their dreams as much as we did. Moreover, as I have students from LGBTI community in my class, most of them identify with me and they feel empowered because someone who is like 'them' is able to become something. In addition, I also cover curriculum content that address homosexuality and as a lecturer who is homosexual I feel very confident when teaching that part, which allows my students to engage more on the issues and express their feelings, which is social justice.

It becomes clear therefore that an engagement with the lived experiences of the past, whether hurtful or negative, has helped these educators think about how they currently act in their various settings.

\section{Discussion and conclusion}

In this project, we set out to engage with decolonisation in two ways. First, we decided to experiment with a different way of doing research that addresses issues of power and privilege in traditional approaches to research and also foregrounds the local experiences of South African teachers. First, in the methodology we chose we found that the autobiographical aspect helped us to engage honestly with our own understandings and that the collaborative aspect helped us to relate that understanding to others. Some of the readings and understandings could have emerged only from our collaborative work and would never have been possible had we done this as individual narratives. Second, we wanted to explore how a theory of anti-oppressive education could be useful when we were making meaning of our narratives in relation to decolonisation and social justice. The theory helped us identify the ways in which our narratives kept an us/them understanding intact to a large extent. In thinking of a way forward, we recognised that as educators we needed to move beyond these binaries into a new understanding of ourselves as assembled subjectivities so that we do not stay stuck in narrow and essentialised definitions of who we are. The theory also helped us to recognise the influence of othering and how our focus on negative experiences underscores the idea that educational spaces can be harmful to learners and educators alike. It became evident that we felt a need to share the harm we had suffered and that in working towards social justice we need to engage with each other's negative memories and experiences of the past in order to reflect on our current moment and move towards a shared responsibility.

We conclude that it is valuable to teachers to reflect on their past experiences in terms of social injustices in order to break the cycle of learners experiencing school as harmful. The importance of foregrounding our micro-social experiences in relation to issues of social justice might work towards change and transformation in the curriculum. Educator identity and experience have been shown to have a major impact on the curriculum (Clandinin, 2000; Clandinin \& Connelly, 2000; Jansen, 2017; Pinar, 2012). It is necessary for the experiential narratives of South African educators to emerge in relation to issues of social justice and 
decolonisation of the curriculum. With this in mind, we find the theory of anti-oppressive education useful to help us share our narratives and at the same time acknowledge the limits of what we know. It makes our everyday actions and interactions relevant in terms of curriculum change and transformation. This became evident in the way in which we were able to recognise how our past experiences with othering, oppression, and hurt could become the core around which we started to think of new ways to be, teach, and learn.

In our project, we worked collaboratively to find the connections between teacher identity, experience, decolonisation, social justice, and anti-oppressive education. Our narratives highlight the messiness and discomfort of our experiences as we relearn, unlearn, and trouble oppressive knowledge in order to imagine alternatives. In the challenging space in which we work, we found the theory of anti-oppressive education useful in our thinking about decolonisation of the curriculum. Our work shows how theory and method can become entangled in working towards a decolonised curriculum. In this article we highlight the unique experiences of five South African teachers in relation to issues of social justice at a time when the call for decolonisation is intensifying.

In closing, we would like to frame our contribution as incomplete and partial. Its value does not lie in giving definite answers of what a decolonised curriculum should be, but, rather, in highlighting the everyday experiences and emotions of those who are working towards transformation and change. A move towards a decolonised curriculum cannot focus on curriculum content alone. Our past experiences shape our present responses to curriculum. Therefore, educator experiences need to be foregrounded as a crucial and important curriculum resource. Troubling the binary thinking and easy categorisation that colonial patterns of thought has entrenched in schooling systems will require us to interrogate our own identities that are still very much shaped by the systems we aim to dismantle. The collaborative theorising of our experiences serves to explore the nuanced complexity of identity and also to highlight the complexity of specific local realities. Therefore, the recognition of the educator as an embodied being with complex emotional responses is crucial in moving towards a decolonised curriculum. Our concluding thought is that a transformed and decolonised curriculum cannot come from outside and be imposed on us as educators in a hierarchical fashion; it should emerge from within us and be with us as we move towards a shared future.

\section{References}

Aoki, T. (2005). Signs of vitality in curriculum scholarship. In W. Pinar \& R. Irwin (Eds.), Curriculum in a new key: The collected works of Ted Aoki (pp. 229-234). Hillsdale, NJ: Lawrence Erlbaum Associates, Inc. Repr. from Aoki, T. (Ed.), 1991. Inspiriting curriculum and pedagogy: Talks to teachers (pp. 23-28). Edmonton, CA: University of Alberta.

Aoki, T. (1993). Legitimating a lived curriculum: Towards a curricular landscape of multiplicity. Journal of Curriculum and Supervision, 8(3), 255-268. 
Bell, L. A. (2007). Theoretical foundations for social justice in education. In M. Adams, L. A. Bell, \& P. Griffen (Eds.), Teaching for diversity and social justice (2nd ed., pp. 1-16). London, UK: Routledge.

Bell, L. A. \& Desai, D. (2011). Imagining otherwise: Connecting the arts and social justice to envision and act for change: Special issue introduction. Equity \& Excellence in Education, 44(3), 287-295.

Chase, S. E. (2011). Narrative Inquiry: Still a field in the making. In N. K. Denzin \& Y. S. Lincoln (Eds.), The SAGE handbook of qualitative research (pp. 421-434). Thousand Oaks, CA: Sage.

Clandinin, D. J., \& Connelly, F. M. (2000). Narrative inquiry. Experience and story in qualitative research. San Francisco, CA: Jossey-Bass.

Cochran-Smith, M., Albert, L., Dimattia, P., Freedman, S., Jackson, R., Mooney, J., . . Zollers, N. (1999). Seeking social justice: A teacher education faculty's self-study. International Journal of Leadership in Education, 2(3), 229-253. doi: 10.1080/13603124.1999.11509466

Cornish, F., Gillespie, A., \& Zittoun, T. (2013). Collaborative analysis of qualitative data. In U. Flick (Ed.), The Sage handbook of qualitative data analysis (pp. 79-93). London, UK: Sage.

Davies, B., \& Gannon, S. (2012). Collective biography and the entangled enlivening of being. International Review of Qualitative Research, 5(4), 357-376.

Denzin, N. K. (2008). Interpretive biography. In J. G. Knowles \& A. L. Cole (Eds.), Handbook of the arts in qualitative research: Perspectives, methodologies, and issues (pp. 117-125). Los Angeles, CA: Sage.

Denzin, N. K. (2017). Critical qualitative inquiry. Qualitative Inquiry, 23(1), 8-16.

Francis, D., \& Hemson, C. (2007). Rainbow's end: Consciousness and enactment in social justice education. Perspectives in Education, 25(1), 99-112.

Freire, P. (1985). Pedagogy of the oppressed. New York, NY: Continuum.

Jansen, J. D. (2009). Knowledge in the blood. Confronting race and the apartheid past. Stanford, CA: Stanford University Press.

Jansen, J. (2017). Sense and non-sense in the decolonization of curriculum. In J. Jansen (Ed.), As by fire. The end of the South African university (pp. 153-171). Cape Town, RSA: Tafelberg.

Keet, A., Sattarzadeh, S. D., \& Munene, A. (2017). Higher education and knowledge otherwise. Education as Change, 21(1), 1-12. 
Kumashiro, K. K. (2000). Toward a theory of anti-oppressive education. Review of Educational Research, 70(1), 25-53.

Kumashiro, K. (2002). Troubling education: Queer activism and anti-oppressive pedagogy. New York, NY: RoutledgeFalmer.

le Grange, L. (2010). South African curriculum studies: A historical perspective and autobiographical account. In W. Pinar (Ed.), Curriculum studies in South Africa: Intellectual histories and present circumstances (pp. 177-200). New York, NY: Palgrave Macmillan.

Mackinlay, E., \& Barney, K. (2014). Unknown and unknowing possibilities: Transformative learning, social justice, and decolonising pedagogy in Indigenous Australian studies. Journal of Transformative Education, 12(1), 54-73.

Mbembe, A. J. (2016). Decolonising the university: New perspectives. Arts \& Humanities in Higher Education, 15(1), 29-45.

Pinar, W. F. (2012). What is curriculum theory? New York, NY: Routledge.

Polkinghorne, D. E. (1995). Narrative configuration in qualitative analysis. International Journal of Qualitative Studies in Education, 8(1), 5-23.

Ulmer, J. B. (2017). Posthumanism as research methodology: Inquiry in the Anthropocene. International Journal of Qualitative Studies in Education, 30(9), 832-848. doi: 10.1080/09518398.2017.1336806

Wyatt, J., Gale, K., Gannon, S., \& Davies, B. (2018). Creating a space in between: Collaborative inquiries. In N. K. Denzin, \& Y. S. Lincoln (Eds.), The Sage handbook of qualitative research (pp. 738-756). Los Angeles, CA: Sage.

Zembylas, M. (2017). Encouraging shared responsibility without invoking collective guilt: Exploring pedagogical responses to portrayals of suffering and injustice in the classroom. Pedagogy, Culture \& Society. doi: 10.1080/14681366.2018.1502206 